\title{
The Study of Stresses on Soil from Roadways Using Plaxis to Generate Potential Energy with Piezoelectric
}

\author{
A. J. M. S. Lim ${ }^{1}$, S. Y. Sim ${ }^{2}$, N. Anting ${ }^{3}$, J. Prasetijo ${ }^{4}$, T. I. T Noor Hasanah ${ }^{5}$, H. H. Goh ${ }^{6}$, \\ Y. M. Y. Buswig ${ }^{7}$, C. C. Kang ${ }^{8}$ \\ ${ }^{1,3,8}$ Faculty of Civil and Environmental Engineering, Universiti Tun Hussein Onn Malaysia, 86400 Parit Raja, Batu Pahat, \\ Johor, Malaysia \\ ${ }^{2,4,5}$ Faculty of Engineering Technology, Universiti Tun Hussein Onn Malaysia, 86400 Parit Raja, Batu Pahat, Johor, \\ Malaysia \\ ${ }^{6}$ Faculty of Electrical and Electronic Engineering, Universiti Tun Hussein Onn Malaysia, 86400 Parit Raja, Batu Pahat, \\ Johor, Malaysia \\ ${ }^{7}$ Deparment of Electrical and Electronic Engineering, Faculty of Engineering, Universiti Malaysia Sarawak, 94300, Kota \\ Samarahan, Malaysia
}

\begin{tabular}{l}
\hline Article Info \\
\hline Article history: \\
Received Feb 11, 2018 \\
Revised Apr 20, 2018 \\
Accepted Apr 27, 2018
\end{tabular}

Keywords:

Effective stress

Piezoelectric

Plaxis

\begin{abstract}
Environmental resources exploitation is one of the critical problems in environmental engineering. The overuse of environmental resources can lead to a huge impact for the environment and human itself. The problems of extracting and processing of raw materials from earth such as mining, steam power and machinery has increased year by year and this is the main reason that the resources has become very limited for the future generations to use them. This study is focused in designing a roadway through software analysis which will use the concept of piezoelectricity that will convert the stress energy from the roadways into electrical energy. A software which is called PLAXIS 2D will be used to simulate the stresses from the roadway which are caused by moving vehicle loading. The parameters of laterite and clay soil such as Specific Gravity, Liquid Limit, Friction Angle and Cohesion are obtained from the past research is needed for the input of the software. The loading application in the PLAXIS 2D uses the Mohr-Coulomb failure criterion in which fully drained and axisymmetric conditions were assumed. A non-uniform grid with 1726 elements was performed for the calculations on a 2-dimensional cross-sections of $11 \mathrm{~m} \times 3 \mathrm{~m}$ roadway. The stresses resulted from the software are used to determine the value of stresses required for the piezoelectric to convert the stress energy into electrical energy.
\end{abstract}

Copyright (C) 2018 Institute of Advanced Engineering and Science. All rights reserved.

\section{Corresponding Author:}

A. J. M. S. Lim,

Faculty of Civil and Environmental Engineering,

Universiti Tun Hussein Onn Malaysia, 86400 Parit Raja, Batu Pahat, Johor, Malaysia.

Email: alvin@uthm.edu.my

\section{INTRODUCTION}

Roadways are main infrastructure for connecting people and providing access and mobility [1]. One of the functions of roadways is load distribution. It can be characterized by the tire loads, tire configurations, repetition of loads, distributions of traffic across the pavement, and vehicle speed. Also, these different types of roads have different widths, in which will have different amount of vehicles passing on them where the many vehicles such as in Kuala lumpur faces congestion on every major avenue, junction or intersection it mostly owes to the offices and the economic and commercial centers during the peak hours [2]. The trafficinduced strains and stresses generated by the vehicles can be potentially used for energy harvesting purposes. 
Harvesting Energy is the best way to approach the global energy problem without disturbing the natural resources. In other words, the key strategy in combatting global warming is to reduce $\mathrm{CO} 2$ emissions [3]. The growing up demand of miniaturizing the device and faster operation is the reason for boosting up the technology to move beyond its limits [4]. Energy harvesting technologies from road infrastructure is a new research that use technologies that capture the wasted energy occurred at pavements, accumulate and store it for later use. Piezoelectric devices are the most suitable for harvesting energy in asphalt pavement roadways. This is because they can convert mechanical strain energy into electric voltage. By using this device, the stresses from vehicle loading on the road can be converted into electrical energy. This study will focus on the mechanical energy that is generated from loads due to vehicles. The distribution of the load will be measured in detail through software analysis using Plaxis 2D and can be a guideline to design piezoelectric installed roadways. The mechanism of piezoelectric on the conversion into electricity will not be discuss in detail in this paper.

\section{PIEZOELECTRIC ON ROADWAY}

By embedding piezoelectric crystals in the asphalt, the compression caused by moving vehicles on the roadway can generate up to 400 kilowatts of energy from a 1 kilometre stretch. This electrical energy produced from the piezoelectric conversion are able to generate enough power for 40 houses. Also, with a more advanced technology, generation of electricity enough to feed the national power grid can be achieved. Governments of developed countries are taking steps in developments in taking advantage of traffic flow into electricity and use it wisely for funding many projects [5].

The crystals in the piezoelectric is usually laid under the surface of the road pavement. As vehicle passes through the road, the piezoelectric crystal will deform slightly. In other words, all the energy that is wasted onto the piezoelectric crystal will be transferred into electricity through the piezoelectric generator. The piezoelectric generator will convert the mechanical energy of the road deformation into electricity. The energy that is converted will either be stored in batteries or connected directly to the grid. It can supply energy to road lighting, traffic lights, speed sensors, and other road facilities that require electric power [5].

The produced deformation and the corresponding potential is generated according to Figure 1 . This will be the source for the lamps for lighting nearby. It is found that when a vehicle moves for every second in a road of $1 \mathrm{~km}$ span that has a piezoelectric under it, a power of $240.12 \mathrm{Kw}$ could be generated. The energy produced is enough to light lamps on the roadside due to the fact that a typical mercury vapour lamp requires around 500W to work. This concept can be applied to pedestrians, airports and railway lines as well. The busier the roadway, the higher the energy that will be produced [5].

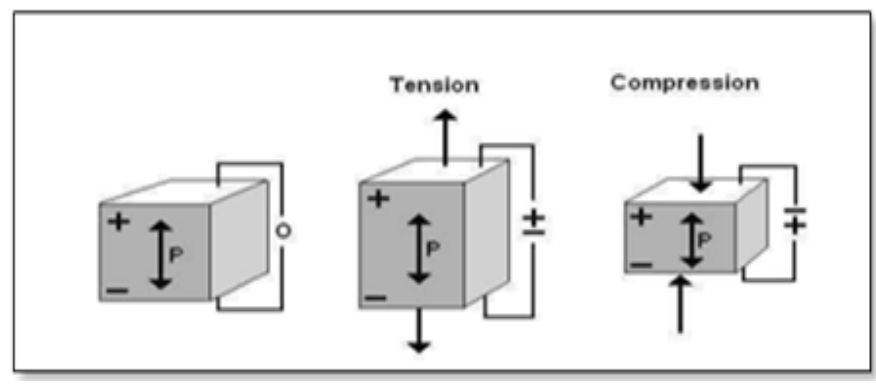

Figure 1. The direct piezoelectric effect

\section{ROAD TYPES}

There are many kind of roads in Civil Engineering field which are divided into several categories. Each categories of road carries out different functions depending on the locations and volumes of vehicles that the road supports. There are two major categories of road which are Rural and Urban Road. These two roads are divided into more sub-categories of roads.

\subsection{Rural Road}

Rural road are defined as a cost saving, low traffic volume, and fair weather roads, mostly traversing agricultural areas and essentially linking villages or clusters of villages and isolated communities amongst themselves or with an arterial road network. The Department of Roads has classified rural roads as district and village roads. The district roads are defined as those roads within the district which serve primarily to 
provide access to abutting land with little or no through movement. These roads give access to one or more villages to the nearest market or higher classes of roads [6]. The category for rural road are Expressway, Highway, Primary Road, Secondary Road and Minor Road [7]. The average traffic count for rural road is 366 vehicles passing [8].

\subsection{Urban Road}

Urban roads are the one located inside towns, cities and other inhabited areas, which are known as urban areas. Roads in urban areas are characterized by busy pedestrian activities and frequent stopping of vehicles which leads to congestion in the area to be built up. Lower design speed are usually designed for urban road. The cross sectional elements applied are also different if compared to rural road. The category of Urban Road are Expressway, Arterial, Collector and Local Street [7] The average daily traffic count for an urban road is 377 vehicles passing [8].

\subsection{Stress on Roads}

Pavement structure reaction to traffic loading is shown by computing the stresses within its layers. If excessively, the stresses acted upon the pavement can cause cracking or surface rutting. This may lead to both structural and functional failure, thus causing a safety hazard to the road users such as motorists and car drivers. Stress $(\sigma)$ is defined as load, in this case caused by a wheel per unit area measure in Mega Pascal. The simplified stress equation for a uniform contact stress with a circular loading is:

$$
\text { Stress }(\sigma)=\frac{1 \times 103 Q}{A}
$$

Road pavements are usually used for low to high volume highway pavements subjected to different truck axle/wheel arrangement. There are three sets of axle configuration which are single, tandem and tridem. As shown in Figure 2, the stress distributions caused by neighboring in a tandem axle are overlapped resulting in a different stress distribution if compared to that of caused by adjacent wheel. Due to the small spacing between the car tyres, the critical pavement responses caused by multiple loading are different than those that are under a single loading [9].

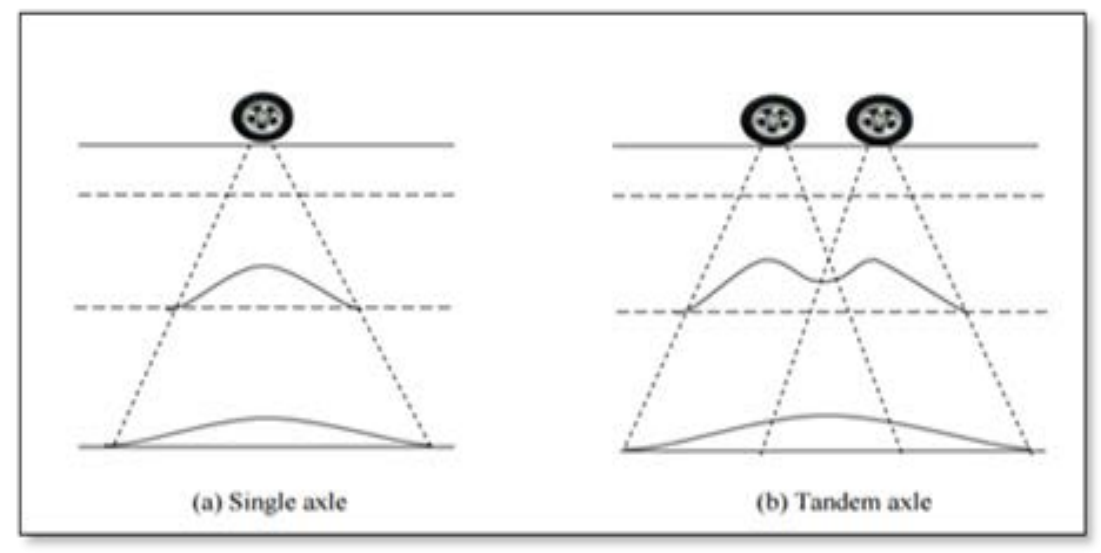

Figure 2. Vertical stress distribution

The intensity of the pressure generated by vehicle is the greatest at the surface of the road and it spreads out into a pyramid-like shape through the layer of the pavement and the bottom soil, which is the subgrade. Every moving wheel will make the road deflect dynamically which will cause compressive stresses in the road structure. There is a system used for determining the design loading, where the damaging effect of axles loading follows an exponential function, which was derived from AASHO Road test. In the road test, there is Power Law, which has the following equivalency formula:

Load Equivalency Factor=Actual axle load (ton) 4.5/Standard axle load (8, 2 ton)

By referring to the equation, if the axle load is doubled the damage will not just be doubled but it will increase twenty times the load due to fact that the damage increases exponentially [10]. 


\section{LOADING APPLICATION}

For load application, Mohr-Coulomb (Mohr-Coulomb failure criterion) were used. Fully drained and plain stream model conditions were assumed. A non-uniform grid with 1726 elements was performed for the calculations on a 2-dimensional cross-sections of $11 \mathrm{~m} \times 3 \mathrm{~m}$. The proposed design will consider putting piezoelectric sensors at certain locations under the soil. The PLAXIS 2D software were used to determine the stresses required.

\subsection{Static Loading}

Static loading were used to simulate the condition when a vehicle is at rest at the traffic light or parking area. The type of loading used were line loading to simulate the area in contact between the car tyre and the road surface. Two line loadings were used because from side view, two tyres were visible for the simulation. For the vehicle load, compact car was assumed with the weight $13.28 \mathrm{kN}$. However, since the line loading were divided into two, the vehicle loading also had to be divided into two, which will make the load as $6.64 \mathrm{kN}$ per axle. Keeping in mind that PLAXIS 2D only allow a width of 1 meter into the z-axis. Hence the load once again have to be divided by two, assuming the vehicle width is 2 meter. Lastly, for the line loading, the area in contact had to be taken measure. Assuming 0.2 meter is the area of contact between tyre and road, the final loading will be $16.6 \mathrm{kN} / \mathrm{m} / \mathrm{m}$.

\subsection{Dynamic Loading}

Dynamic loadings were used to simulate the moving vehicle on the road. 4 speeds were used which were $60 \mathrm{~km} / \mathrm{h}, 100 \mathrm{~km} / \mathrm{h}, 120 \mathrm{~km} / \mathrm{h}$ and $150 \mathrm{~km} / \mathrm{h}$. By using ratio and assuming piezo sensor size is $0.15 \mathrm{~m}$ in diameter, the time required for the vehicle to move a certain distance were determined. The way dynamic loading were applied was by using load multiplier in PLAXIS 2D. Figure 3 shows the schematic diagram of a roadway and its stress markers that needs to be measured. The time of the multipliers varies with the speed of the vehicle. By assuming the piezo sensor diameter was $0.15 \mathrm{~m}$, the time for the vehicle tyre to travel in a distance onto the piezo sensor can be determined. With the speed of $150 \mathrm{~km} / \mathrm{h}$, it will take 0.0009 s for the tyre to reach the multiplier value of 0.5 , which is a quarter of the piezo sensor diameter. This means that the loading of the vehicle is half at this point. This calculation was calculated by using ratio.

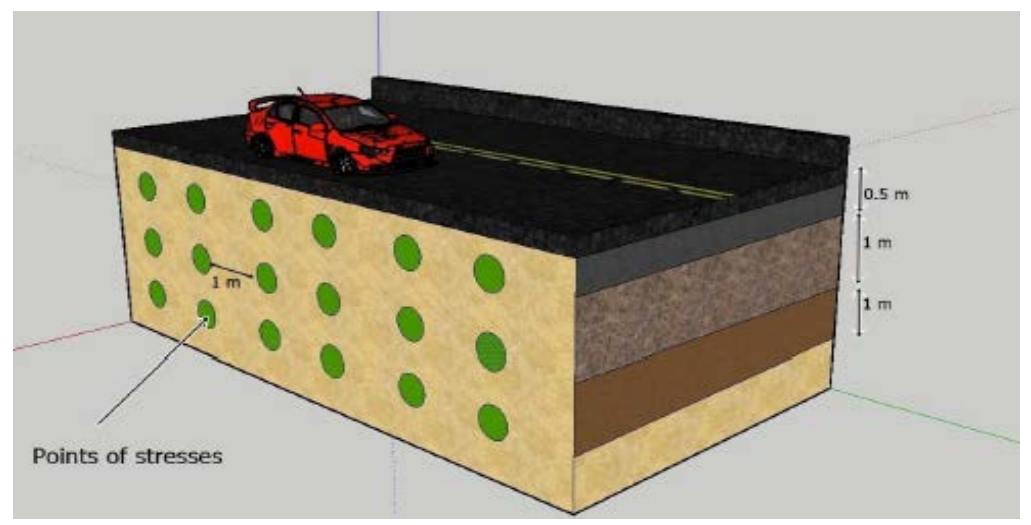

Figure 3. Schematic diagram for the model anaylsis

\section{RESULTS AND DISCUSSIONS}

Figure 4, 5, 6 and 7 shows the values of effective stress values caused by dynamic loadings with speeds of $60 \mathrm{~km} / \mathrm{h}, 100 \mathrm{~km} / \mathrm{h}, 120 \mathrm{~km} / \mathrm{h}$ and $150 \mathrm{~km} / \mathrm{h}$ at different depths respectively from the left side of the simulated model. The highest Effective Stress for speed $60 \mathrm{~km} / \mathrm{h}, 100 \mathrm{~km} / \mathrm{h}, 120 \mathrm{~km} / \mathrm{h}$ and $150 \mathrm{~km} / \mathrm{h}$ are $21.710 \mathrm{kN} / \mathrm{m} 2,20.71 \mathrm{kN} / \mathrm{m} 2,19.46 \mathrm{kN} / \mathrm{m} 2$ and $18.65 \mathrm{kN} / \mathrm{m} 2$ respectively. All the highest values of Effective Stress are at the depth of $0.5 \mathrm{~m}$ below the surface Hence, based on the simulation and analysis, as the speed increases, the stress value was found decreasing. 


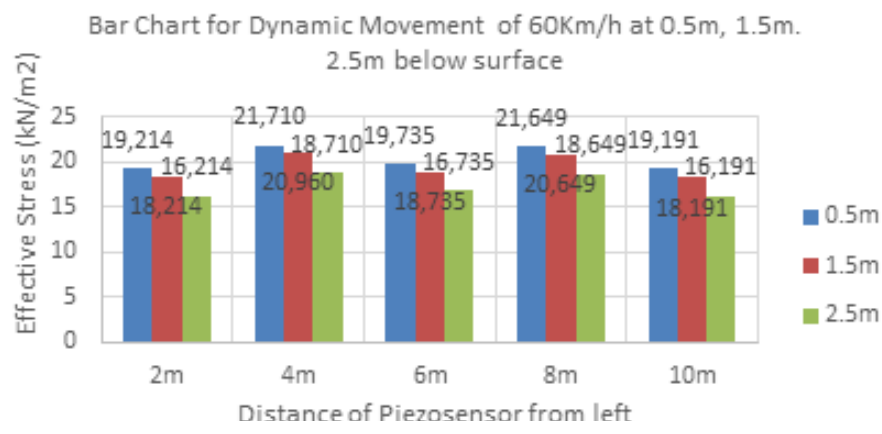

Figure 4. Effective stress caused by $60 \mathrm{~km} / \mathrm{h}$ dynamic loading

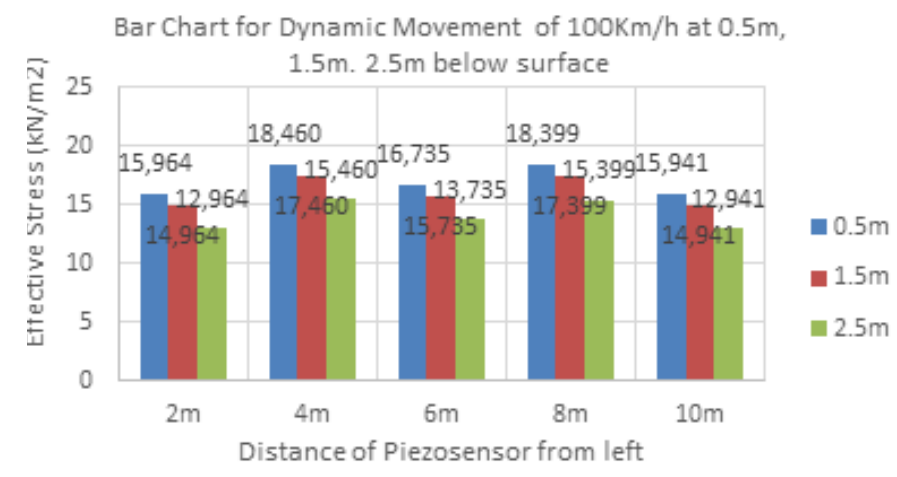

Figure 5. Effective stress caused by $100 \mathrm{~km} / \mathrm{h}$ dynamic loading

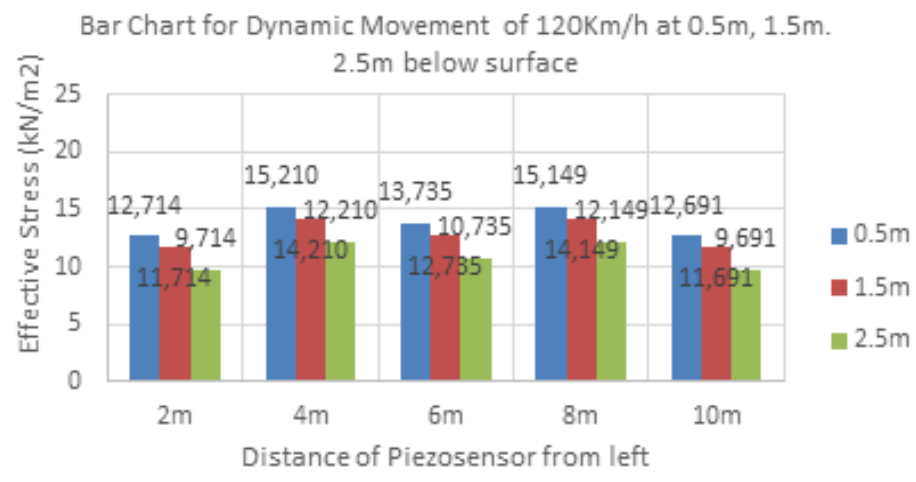

Figure 6: Effective stress caused by $120 \mathrm{~km} / \mathrm{h}$ dynamic loading

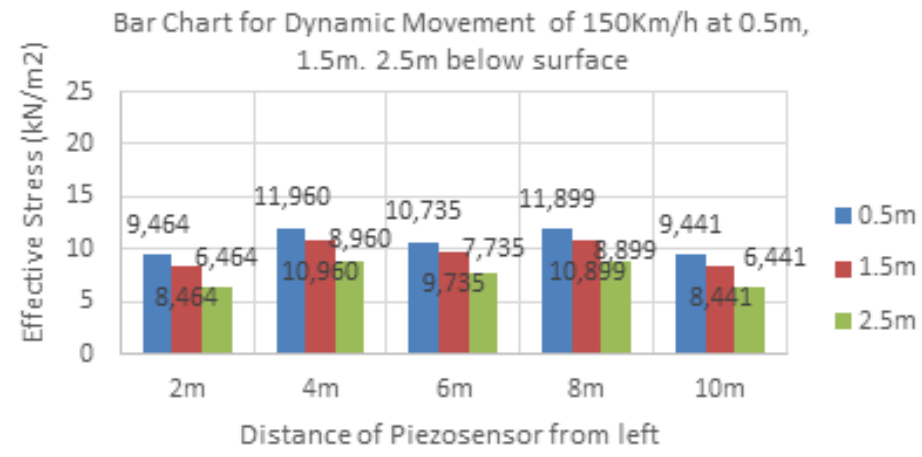

Figure 7. Effective stress caused by $150 \mathrm{~km} / \mathrm{h}$ dynamic loading 
Based on the simulation of PLAXIS that was carried out, the effective stress for a dynamic loading, which is a moving vehicle decreases as the vehicle travel in faster speeds. The reason for this to happen is due to the point in which the piezo sensor was placed. When a piezo sensor is placed only at a certain small area point, the contact time between the tyre and the sensor is limited and very little. This caused the loading from the vehicle to not be able to transfer a lot of force. The analysis also showed that the stresses under the soil are higher at some other points, such as at the side portion of the distribution. When the force goes deeper, the stress will be distributed in a way that edge of the distribution range are higher than directly underneath the loading point. Hence, in order for the piezo sensor to be functioned well, it has to be placed in several points underneath the road. This way, the loading of the vehicle will be distributed well and the time in contact between the vehicle tyre and the piezo sensor can be increased.

\section{CONCLUSION}

From results obtained in parametric study, it was found that the faster the vehicle speed, the lower the effective stress values that were obtained. This is due to the fact that the assumption that the vehicle weight is remained constant. When the vehicle weight is remained constant, the loading will be the same when the vehicle passes through the piezo sensor point. However, since the piezo sensor point only make contact with the vehicle tyre for short period of time, the loading of the vehicle will not be affecting the piezo sensor so much. As a suggestion, based on the stresses and dynamic loading at $0.5 \mathrm{~m}$, the most suitable location for the piezo sensor to be embedded is at $0.5 \mathrm{~m}$ underneath the soil because that is where the effective stress has the highest value. This will allow higher energy conversion.

\section{ACKNOWLEDGEMENT}

The authors would like to acknowledge Universiti Tun Hussein Onn Malaysia (UTHM) and and the Ministry of Higher Education (MOHE) for the financial support for this study under the research grant FRGS VOT. 1626.

\section{REFERENCES}

[1] Jiang, Wei \& Yuan, Dongdong \& Xu, Shudong \& Hu, Huitao \& Xiao, Jingjing \& Sha, Aimin \& Huang, Yue. Energy harvesting from asphalt pavement using thermoelectric technology, Applied Energy, Elsevier, 2017. Vol. 205(C), pages 941-950.

[2] Bhargava, S \& Rao S.P.V.S. Study of different Parametric Variations of MOSFET Pressure Sensor. Indonesia Journal of Electric Engineering and Computer Science (IJEECS). 2018. Vol 10(1), pp 19 - 26.

[3] Hashim, A., Lo, K.L. Thermal Effect of Wind Generation on Conventional Generator in a Microgrid. Indonesia Journal of Electric Engineering and Computer Science (IJEECS). 2018. Vol 10(3).

[4] Ali, M., Manogaran, S., Yusof K.M., Suhaili, M.R.M. Analysing Vehicular Congestion Scenario in Kuala Lumpur Using Open Traffic. Indonesia Journal of Electric Engineering and Computer Science (IJEECS). 2018. Vol 10(3).

[5] Kumar, P. Piezo-Smart Roads, International Journal of Enhanced Research in Science Technology; 2013; 2(6), pp 65-60.

[6] Paudyal, D. P., Improvement and Sustainable Development. Nepal: International Centre for Integrated Mountain Development.1998.

[7] Public Works Department Malaysia, Malaysian Highway Authority, Institution of Engineers Malaysia, Institution of Highways \& Transportation.A Guide on Geometric Design Of Roads. Malaysia: Road Engineering Association of Malaysia (REAM). 2002

[8] Seaver, W. L., Chatterjee, A. \& Seaver, M. L. Estimation of Traffic Volume on Rural Local Roads. Transportation Research Record, Journal of the Transportation Research Board. 2014; (1335), pp 123.

[9] Kim, M. Three-Dimensional Finite Element Analysis of Flexible Pavements Considering Nonlinear Pavement Foundation Behaviour. PhD Thesis. University of Illinois. 2007.

[10] N Baatar, S Kim. A Thermoelectric Generator Replacing Radiator for Internal Combustion Engine Vehicles. TELKOMNIKA (Telecommunication, Computing, Electronics and Control). 2011; 9(3): 523-530. 